\title{
Trajetórias de profissionalização docente da mulher educadora: monitoras de creche em Naviraí, MS
}

\section{The teaching professionalization path of female educators: day-care monitors in Naviraí, MS}

\section{La trayectoria de profesionalización docente de la mujer educadora: monitoras de guardería en Naviraí, MS}

\author{
Larissa Wayhs Trein Montiel ${ }^{1}$ \\ Míria Izabel Campos²
}

DOI: http://dx.doi.org/10.20435/serie-estudos.v26i57.1430

\begin{abstract}
Resumo: $O$ atendimento coletivo das crianças nas creches no Brasil se pautou pela ideia preconcebida de que a mulher, por sua natureza feminina, seria mais bem preparada para assumir as funções naqueles espaços. Nesse contexto, o objetivo geral neste texto foi dar visibilidade às trajetórias de profissionalização docente de mulheres educadoras de Naviraí, Mato Grosso do Sul. Para tanto, elencaram-se como objetivos específicos saber quando se tornaram monitoras de creche; quais motivos e/ou interesses as levaram à escolha profissional; como questões de gênero permearam e refletiram nas trajetórias de vida e profissão; e de que forma compreenderam a necessidade de uma profissionalização docente para se estabelecerem na carreira. Utilizou-se como recurso metodológico a História Oral temática, tendo sido realizadas entrevistas, as quais foram analisadas à luz do referencial teórico eliasiano. Percebeu-se que as políticas educacionais pensadas para o atendimento à criança pequena geraram uma alteração na carreira destas profissionais, e isso se refletiu em suas trajetórias de formação docente. Compreendeu-se que rememorar os aspectos envolvidos no percurso de suas vidas e trajetórias profissionais possibilitou o entendimento de como as figurações, isto é, as redes de interdependência, foram constituídas pelas mulheres educadoras e ao mesmo tempo as constituíram, trazendo à tona questões de gênero e poder inerentes aos diferentes tempos e espaços de trabalho e formação.
\end{abstract}

Palavras-chave: profissão docente; gênero; figurações.

Abstract: The collective work with children in day-cares in Brazil has been guided by the preconceived idea that a woman would be better suited to take on the responsibilities in that space because of her feminine nature. In this context, the general purpose of this paper was to give visibility to the professionalization path of female educators from Naviraí, Mato Grosso do Sul state. Therefore, we listed four specific aims: to know when they became day care centre monitors; 
what reasons and/or interests led them to choose this job; how gender issues permeated and reflected on their life and career's path; and last but not least, how they understood the need for teacher training in order to settle in their career. As methodological resource, we used the Oral History topic, as we conducted some interviews which were analyzed in the light of the eliasiano theoretical framework. We found out that the educational policies thought for the work with small children generated a change on these workers careers and these changes reflected on the teachers' development paths. We comprehended that remembering the aspects involved both in their life and in their professional path made it possible to understand how the figurations, in other words, the interdependency network, were constituted by the women educators and, at the same time, the women constituted themselves, bringing up gender and power issues, inherent to the different time and space of work and education.

Keywords: teaching profession; gender; figurations.

Resumen: La atención colectiva a los niños en las guarderías en Brazil se ha fundamentado en la idea preconcebida de que la mujer, debido a su naturaleza femenina, sería más capacitada para asumir las funciones en aquellos espacios. En este contexto, el principal objetivo del presente trabajo es dar visibilidad a las trayectorias de profesionalización docente de mujeres educadoras de Naviraí, Mato Grosso do Sul. Para ello, se ha buscado lograr los siguientes objetivos específicos: saber cuándo se hicieron monitoras de guardería; cuáles motivos y/o intereses las llevaron a elegir su profesión; cómo cuestiones de género influyeron y se reflejaron en sus trayectorias de vida y profesional; y, también, cómo comprendieron la necesidad de una profesionalización docente para consolidarse profesionalmente. Como recurso metodológico se ha utilizado la Historia Oral temática. Se ha realizado encuestas, las cuales fueron analizadas a la luz del marco referencial teórico de Norbert Elias. Se ha notado que las políticas educativas destinadas a la atención del niño pequeño han generado un cambio en la trayectoria profesional de esas mujeres, y eso se ha reflejado em su formación docente. Se ha comprendido que recordar los factores que intervinieron en el transcurso de sus vidas y trayectorias profesionales han posibilitado el entendimiento de cómo las figuraciones, es decir, las redes de interdependencia, han sido construidas por las mujeres educadoras y, a la vez, les han formado a ellas, poniendo de relieve cuestiones de género y poder inherentes a los diferentes tiempos y espacios de trabajo y formación.

Palabras clave: profesión docente; género; figuraciones.

\section{INTRODUÇÃO}

Ao logo da história, especialmente da História da Educação, o atendimento coletivo das crianças nas creches em nosso país se pautou pela ideia preconcebida de que a mulher, por sua natureza feminina, seria mais bem preparada para assumir as funções naqueles espaços. Sendo assim, a trajetória profissional de mulheres que atuaram na educação de crianças no período em que o atendimento era ofertado pela Assistência Social e passou para a Educação Infantil se constituiu pano de fundo das nossas pesquisas. 
Nesse contexto, no presente artigo, partimos da perspectiva de que estudar a trajetória profissional de mulheres que atuaram na educação de crianças poderá colaborar e estimular a reflexão quanto à formação de novos professores/ as e, também, contribuir para reconstrução da história da profissão docente na Educação Infantil em Mato Grosso do Sul (MS) ${ }^{3}$, bem como proporcionar uma análise sobre as questões de gênero referentes ao lugar social da mulher e de trabalho na carreira do magistério. Como bem pontuou Pavan (2018, p. 195), "[...] a educação é um fenômeno social, cultural, político e econômico que, como tal, não pode ser pensado fora desses condicionantes".

Assim, nosso objetivo geral, neste texto, foi dar visibilidade às trajetórias de profissionalização docente de mulheres educadoras de Naviraí, MS. Para tanto, elencaram-se como objetivos específicos saber quando se tornaram monitoras de creche; quais motivos e/ou interesses as levaram à escolha profissional; como questões de gênero permearam e refletiram nas trajetórias de vida e profissão; e de que forma compreenderam a necessidade de uma profissionalização docente para se estabelecerem na carreira.

De acordo com Alberti (2006, p. 164), "[...] a história oral é hoje um caminho interessante para se conhecer e registrar múltiplas possibilidades que se manifestam e dão sentido a formas de vida e escolhas de diferentes grupos sociais, em todas as camadas da sociedade". Neste cenário, nós partimos da perspectiva de que estudos realizados por meio da História Oral permitem compreendermos a relação dos sujeitos com a própria história, bem como tratarmos sobre a preservação da memória.

É importante acrescentarmos, também, que entendemos a História Oral como um termo abrangente, que pode ser classificado em tipos/gêneros/espécies. Ozella (2003) e Lang (1996) nos ajudam nesse sentido, quando discutem o tema escrevendo acerca do que diferencia/caracteriza sua aplicação, chamando atenção para suas especificidades metodológico-epistemológicas, sendo as técnicas adotadas consequências da forma de agir do/a pesquisador/a. Em consequência dessas possibilidades, optamos por utilizar como recurso metodológico a História

\footnotetext{
${ }^{3}$ Este artigo tem origem e amplia discussões de pesquisa concluída no Programa de Pós-Graduação em Educação (PPGEdu) da Universidade Federal da Grande Dourados (UFGD), na Tese de Doutorado em Educação intitulada "Da Assistência à Educação Infantil: a transição do atendimento à infância no município de Naviraí- MS (1995-2005)" (MONTIEL, 2019).
} 
Oral temática, que, de acordo com Freitas (2006, p. 21), é um dos gêneros possíveis dessa metodologia, pois "[...] a entrevista tem caráter temático e é utilizada com um grupo de pessoas sobre um assunto específico".

Por esse prisma, realizamos cinco entrevistas, que foram gravadas em áudio, transcritas, textualizadas e analisadas à luz do referencial teórico eliasiano (ELIAS, 1993, 2006, 2008). Assim, para compor nosso texto, trazemos no Quadro 1 dados das cinco monitoras de creche que participaram do estudo, discorreram que tinham o primeiro ou segundo grau (nomenclatura da época) e, com a mudança da legislação, a partir da Constituição Federal (BRASIL, 1988), precisaram buscar uma formação específica para permanecerem no cargo que exerciam no município de Naviraí, MS. Portanto as cinco mulheres educadoras tiveram de adequar suas vidas pessoais e profissionais diante da nova necessidade e demanda da profissão, relatando que tais mudanças foram percebidas e alteraram as relações de trabalho na instituição em que atuavam.

Quadro 1 - Apresentação das entrevistadas - As monitoras de creche (1995$2005)^{4}$

\begin{tabular}{|c|c|c|}
\hline NOME & FUNÇÃO EXERCIDA E QUE EXERCE HOJE & IDADE ATUAL \\
\hline $\begin{array}{c}\text { Andréa José dos } \\
\text { Santos Galvão }\end{array}$ & $\begin{array}{c}\text { Monitora de creche. Hoje atua como } \\
\text { coordenadora pedagógica em instituição de } \\
\text { Educação Infantil }\end{array}$ & 46 anos \\
\hline $\begin{array}{c}\text { Geni Messias } \\
\text { Alves Barreto }\end{array}$ & $\begin{array}{c}\text { Monitora de creche. Hoje atua como diretora } \\
\text { de instituição de Educação Infantil }\end{array}$ & 49 anos \\
\hline $\begin{array}{c}\text { Sandra Pedro da } \\
\text { Silva Souza }\end{array}$ & $\begin{array}{c}\text { Monitora de creche. Hoje atua como } \\
\text { assistente administrativa escolar em uma } \\
\text { escola municipal }\end{array}$ & 47 anos \\
\hline $\begin{array}{c}\text { Sônia da Silva } \\
\text { Felix }\end{array}$ & $\begin{array}{c}\text { Monitora de creche. Hoje atua como } \\
\text { assistente administrativa escolar em uma } \\
\text { escola municipal }\end{array}$ & 54 anos \\
\hline $\begin{array}{c}\text { Vera Lúcia da } \\
\text { Silva }\end{array}$ & $\begin{array}{r}\text { Monitora de creche. Hoje atua na Gerência de } \\
\text { Cultura de Naviraí, MS }\end{array}$ & 49 anos \\
\hline
\end{tabular}

Fonte: Organização Montiel (2019).

\footnotetext{
${ }^{4}$ As monitoras de creche Andréa, Geni, Sandra, Sônia e Vera aceitaram participar da pesquisa, assinaram o Termo de Consentimento Livre e Esclarecido (TCLE), bem como concordaram que seus nomes fossem divulgados nas publicações do estudo.
} 
Para contarmos da pesquisa, além desta introdução, construímos três seções, sendo que, na primeira, tecemos considerações acerca da perspectiva metodológica da História Oral temática. Posteriormente, na segunda seção, apresentamos sobre a mudança da legislação e sua repercussão na vida pessoal e profissional das monitoras de creche de Naviraí, MS. Na terceira, mostramos o lócus da pesquisa, registrando brevemente sobre o município de Naviraí, MS, e refletimos sobre a profissionalização docente a partir do que nos contaram as mulheres, monitoras de creches. E, finalizando, trazemos considerações finais, objetivando arrematar nossas reflexões acerca da temática proposta para este texto.

\section{METODOLOGIA EM QUESTÃO: HISTÓRIA ORAL TEMÁTICA}

A metodologia apresentada neste trabalho se constitui de estudos da História Oral, a partir do seu "gênero história temática", ou seja, a entrevista "[...] que tem característica de depoimento - não abrange necessariamente a totalidade da existência do informante" (FREITAS, 2006, p. 20-1). Nosso interesse, como nós já registramos anteriormente, concentrou-se na experiência das mulheres no trabalho educativo com as crianças.

Também nos fundamentamos em Alberti (2006, p. 166), complementando a partir de seus estudos que "[...] a riqueza da história oral está evidentemente relacionada ao fato de ela permitir o conhecimento de experiências e modos de vida de diferentes grupos sociais". Ainda apoiadas na mesma autora, salientamos seus escritos quando ela aponta que vale trabalharmos com a História Oral temática, pois "[...] são as que versam prioritariamente sobre a participação do entrevistado no tema escolhido, possuindo uma relação com o método biográfico centrado no tema" (ALBERTI, 2006, p. 166).

Assim, pudemos, por meio da entrevista semiestruturada com cinco monitoras, compreender o quanto a História Oral possibilita valorizar todos aqueles que estejam representados nas pesquisas e investigações, realçando as vozes das pessoas, dando visibilidade às suas trajetórias de vida, memórias e biografias, histórias que podem dar respostas a nossos questionamentos (SARAT; SANTOS, 2010).

Utilizamos como fonte as lembranças das monitoras de creche e os relatos das experiências de um passado recente, trilhando os caminhos percorridos e ressignificados. Lembrar nos possibilita enriquecer nossas vivências dando cor, 
profundidade e significado, armazena um pouco de tudo que foi vivido, experimentado. Dados, sensações, sentimentos e saberes estão aí guardados, segundo um código de acesso próprio e quase desconhecido do indivíduo que lembra (CUNHA, 1997).

As conversas/entrevistas se deram em sessões individuais, sendo usado como instrumento de pesquisa um roteiro para a realização da entrevista semiestruturada. O relato oral foi guiado pelo interesse das pesquisadoras em conhecer o que elas - as monitoras - tinham a dizer sobre o tema da pesquisa. Cada entrevista durou cerca de uma hora e vinte minutos. Sob esse enquadramento, precisamos destacar que tanto as pesquisadoras como as monitoras participantes da pesquisa pertencem ao mesmo domínio de práticas, à mesma profissão. Assim, segundo Cunha (2017, p. 26), "[...] conseguimos construir um vínculo recíproco de confiança e afinidades".

E é exatamente nessa perspectiva as assertivas de Thompson (2002, p. 197), quando ele aponta que "toda fonte histórica derivada da percepção humana é subjetiva, mas apenas a fonte oral permite-nos desafiar essa subjetividade: descolar as camadas de memória, cavar fundo em suas sombras, na expectativa de atingir a verdade oculta".

Nesse contexto metodológico, a escolha das profissionais para participar da pesquisa, as cinco monitoras de creche, concentrou-se em mulheres que atuaram na Assistência Social e, depois da legislação, passaram para a Gerência de Educação e Cultura (nomenclatura de instâncias municipais de Naviraí, MS). Ou seja, profissionais que vivenciaram o período de adaptação da formação, visando atender à nova exigência legal.

Para Gonçalves (2004, p. 71), "a entrevista possibilita uma interação face a face, sendo revestidas de formas e conteúdo, possibilitando diversos consoantes como o interlocutor, o momento, a função, o centro de interesse, o alvo, o grau de liberdade e o nível de profundidade". Nesse sentido, tem-se a possibilidade de discorrer sobre o tema proposto.

As perguntas foram previamente definidas em um conjunto de questões, entretanto procuramos possibilitar um contexto de uma conversa informal, mas sempre que necessário buscamos dirigir o foco do diálogo para elucidar as questões que ainda restavam duvidosas. Esse tipo de entrevista é muito "[...] utilizado quando se deseja delimitar o volume das informações, obtendo assim um dire- 
cionamento maior para o tema [...]" (BONI; QUARESMA, 2005, p. 75).

Exposta nossa trajetória metodológica, importante enaltecermos que "[...] o passado humano não é um agregado de histórias separadas, mas uma soma unitária do comportamento humano" (THOMPSON, 1981, p. 50). E, diante de tal perspectiva, procuramos apresentar, a partir de documentos gerados pelas entrevistas, uma "soma unitária do comportamento humano", uma "rede", denotando como a totalidade da relação entre indivíduo e sociedade pode fazer a história, pois esta é resultado de ações e associações entre os indivíduos e as relações sociais, que pretendem ser explicitadas a partir da pesquisa (ELIAS, 2006).

Nesse sentido, valendo-nos de Souza (2016, p. 4), ressaltamos que “[...] a memória, entendida como documento, fornece ao historiador indícios que permitem a produção de leituras do passado [...]", e estas, de alguma forma, encontram-se ancoradas na história individual, emergindo nas manifestações das lembranças. Por conseguinte, a partir do referencial teórico-metodológico, isto é, de acordo com nossa escolha pela abordagem eliasiana, nós evidenciamos que as análises das informações são pautadas em indícios e pistas que prenunciam os caminhos, aproximam e distanciam as experiências vividas pelos indivíduos, possibilitando-nos contribuir para a escrita das suas histórias.

\section{UMA NOVA EXIGÊNCIA PROFISSIONAL: REDES QUE AJUDAM A ESCREVER A HISTÓRIA}

A profissão docente foi uma das primeiras e principais ocupações que a mulher desenvolveu fora do lar, compondo parte fundamental do processo de desenvolvimento da educação, e ocorreu por diversos fatores. Assim, importante ressaltarmos que esse movimento aconteceu principalmente no magistério primário, ou seja, na atuação com crianças, pois no nível secundário e no superior a predominância da docência masculina se manteve por um longo período (ENGUITA, 1991; NÓVOA, 1991).

No município de Naviraí, MS, lócus da nossa pesquisa, as monitoras de creche começaram a vivenciar as novas mudanças, pois já atuavam com as crianças nesse espaço, mas não tinham a formação mínima - o magistério - que começou a ser exigida pela legislação nacional. Listamos aqui os documentos cujos objetivos eram regulamentar as novas exigências da formação e que, de diversas maneiras, 
impactaram a vida e a profissão das entrevistadas: Constituição Federal (BRASIL, 1988); Lei Orgânica da Assistência Social (BRASIL, 1993); Política de Formação do Profissional de Educação Infantil (BRASIL, 1994a); Política de Educação Infantil (BRASIL, 1994b); Lei de Diretrizes e Bases da Educação Nacional (BRASIL, 1996).

Entendemos ser significativo tratarmos rapidamente de cada um dos documentos citados. Assim, registrando uma trajetória legal, no final dos anos de 1980, temos a promulgação da Constituição Federal (BRASIL, 1988), que passou a assegurar o reconhecimento da criança enquanto cidadão e sujeito de direito, quando vimos ampliar, também, a visão da criança não mais como um menor carente ou necessitado, mas a visão de uma criança cidadã de direitos, um indivíduo completo e que requer atendimento integral.

Posteriormente, em 1993, foi aprovada a LOAS, Lei n. 8.742, de 7 de dezembro de 1993, determinando mudanças na política de assistência social. Verificamos, em análise no documento, um movimento de mudança no atendimento ofertado pela Assistência Social, buscando uma divisão de atividades por meio de um sistema participativo, prevendo, assim, várias iniciativas ao longo dos anos, gerando impactos na trajetória do atendimento à criança de 0 a 6 anos (BRASIL, 1993).

Observamos, nos anos pós-constituição, ainda tramitando a nova Lei de Diretrizes e Bases da Educação Nacional (LDBEN), Lei n. 9.394 (BRASIL, 1996), que eram muitas as indefinições sobre como o Estado, em suas três instâncias, garantiria os preceitos constitucionais, entre eles, o direito das crianças de 0 a 6 anos à educação. Diante desses desafios, o Ministério da Educação (MEC), nos anos de 1992-1994, instituiu a Coordenação Geral de Educação Infantil (COEDI). Sendo assim, no mesmo contexto, são elaborados dois documentos para se pensar a Educação Infantil: "Política de Formação do Profissional de Educação Infantil", em abril de 1994; e "Política Nacional de Educação Infantil", em dezembro de 1994. Tais documentos serviram de referência para as discussões da LDBEN de 1996, que, promulgada em 20 de dezembro de 1996, afirmou a Educação Infantil como a primeira etapa da Educação Básica:

Art. 29. A Educação Infantil, primeira etapa da educação básica, tem como finalidade o desenvolvimento integral da criança de até 5 (cinco) ${ }^{5}$ anos, em

\footnotetext{
${ }^{5}$ Redação dada pela Lei n. 12.796 (BRASIL, 2013); até então, o texto se apresentava desta forma: “Art. 29. A Educação Infantil, primeira etapa da educação básica, tem como finalidade o desen-
} 
seus aspectos físico, psicológico, intelectual e social, complementando a ação da família e da comunidade. Art. 30. A Educação Infantil será oferecida em: I- Creches, ou entidades equivalentes, para crianças de até três anos de idade; II- Pré-escolas, para as crianças de 4 (quatro) a 5 (cinco $)^{6}$ anos de idade. (BRASIL, 1996).

Além disso, a LDBEN determinou também que as creches fossem integradas aos respectivos sistemas de ensino, como lemos no Art. 89. "As creches e pré-escolas existentes ou que venham a ser criadas deverão, no prazo de três anos, a contar da publicação desta Lei, integrar-se ao respectivo sistema de ensino" (BRASIL, 1996). Diante das normativas legais, somente em 2007, sob a nova política de Assistência Social, o Ministério do Desenvolvimento Social (MDS) autorizou os municípios que transferissem a rede de Educação Infantil da Secretaria de Assistência Social para a de Educação, e até 2009 foi concluído o processo de transição da gestão da rede de Creches do MDS para o Ministério da Educação. Para essa transferência, foi criado um Comitê Técnico Interministerial (CTI) do MDS, do MEC e do Ministério do Planejamento, consolidando o entendimento.

Vale destacarmos que, ao longo do processo, a administração municipal tentou se adaptar às novas demandas legais, mesmo sem levar em conta as necessidades dos grupos que já atuavam em serviço. Quando perguntamos para as entrevistadas, monitoras de creche, se elas conheciam a legislação sobre a Educação Infantil, todas demostraram desconhecer sobre a possibilidade de formação em serviço para habilitação no nível médio/normal. Diante disso, os anos de atuação com as crianças nas creches não eram mais uma possibilidade de trabalho para estas mulheres, e foi preciso se adequar ao novo cargo de assistente administrativa escolar ou procurar outras possibilidades na carreira profissional, com a formação docente adequada. Sendo assim, muitas buscaram cursos fora da cidade para garantir o trabalho de professora.

As monitoras de creche nos contaram sobre as mudanças no seu quadro funcional e, ainda, acerca das novas adaptações que precisaram fazer para permanecerem trabalhando, indicando os processos de ocupação de um cargo que

volvimento integral da criança até seis anos, em seus aspectos físico, psicológico, intelectual e social, complementando a ação da família e da comunidade".

${ }^{6}$ Redação dada pela Lei n. 12.796 (BRASIL, 2013), de 4 de abril de 2013; até então, o texto se apresentava desta forma: "II- Pré-escolas, para as crianças de quatro a seis anos de idade". 
caminhou da improvisação e do amadorismo para a profissionalização requisitada pela legislação. As referências legais criaram e exigiram que o docente, professor de Educação Infantil, fosse um indivíduo com formação específica e saberes polivalentes, e, como essas mulheres não possuíam tal formação naquele momento, necessitaram ir à busca de se reinventarem. Sobre as novas exigências, temos o seguinte relato de Geni:

Antes podia só Magistério. Só poderia fazer o concurso quem tinha o Magistério e ser monitora de creche, educador de creche. Era monitor depois passou para educador de creche, a maioria não tinha Magistério. Acho que das 117, nenhuma tinha. A Dona Cleusa [Gerente de Educação] na época fez o nosso concurso para ser Assistente Administrativo Escolar e trabalhar nas secretarias, mas foi muito ruim, foi péssimo.

Nessa perspectiva, o processo de mudança de grupos com uma figuração distinta se altera a partir de uma exigência normativa. Portanto as redes de interdependência de grupos específicos, que antes coexistiam pautadas em determinados conhecimentos comum a todas, transformam-se, pois uma nova reivindicação estava em curso. Assim, para cumprir a exigência da profissionalização e da especificidade necessária, elas - as monitoras - precisaram ir em direção a novas redes de interdependência e outras figurações para conseguirem seu lugar no grupo daquelas mulheres que tinham a formação profissional necessária (ELIAS, 2006).

\section{TRAJETÓRIAS DE FORMAÇÃO: RELATOS DAS MULHERES EDUCADORAS}

Antes de adentrarmos para as reflexões a partir dos relatos das mulheres educadoras, mostraremos a seguir o lócus da pesquisa, registrando brevemente sobre o município de Naviraí, MS, tendo como referência, principalmente, Montiel (2019).

Naviraí situa-se no Estado de Mato Grosso do Sul, mesorregião do sudoeste do estado e microrregião de Iguatemi. O município foi fundado em 16 de abril de 1952, pela colonizadora Vera Cruz Ltda - empresa comercial constituída por 18 sócios, registrada na Junta Comercial do Estado de São Paulo, sob n. 206.916, tendo

\footnotetext{
${ }^{7}$ Como pode ser constatado em documentos, foram 11 concursadas como Monitoras de Creche em Naviraí, destas nenhuma tinha o curso de Magistério ou Normal e foram transferidas pela gerente de educação para cargos de Assistentes Administrativos em secretarias de escolas.
} 
como diretores: Ariosto da Riva, Batista Otoloni e Vicente Geraldo Scarabotolo ${ }^{8}$ Em 11 de novembro de 1963, emancipou-se do município de Caarapó.

As primeiras famílias de colonos se instalaram onde hoje é o Rancho São Lucas, local, à época, habitado por índios guaranis. Naviraí conta com uma localização estratégica que leva ao acesso às principais regiões do Brasil, como os estados de São Paulo, Paraná, Santa Catarina e Mato Grosso (NAVIRAí, 2015).

A partir de 1953, instalam-se as primeiras indústrias madeireiras no município, tal a abundância de madeiras nobres na região, chegando a ter por volta de 44 indústrias madeireiras. Em 1955, a vila de Naviraí foi unida à cidade de Caarapó e Dourados, começando o ciclo da produção de café, algodão, erva-mate e a industrialização de madeiras. Já em 1956, foram construídas as primeiras salas de aula do município.

Posteriormente, no ano de 1967, tiveram início aulas das 5a séries no Ginásio Estadual de Naviraí e, em 1968, chegou a Naviraí um grupo de professores para compor o corpo docente desse primeiro ginásio: Júlio Garcia Gagnin, Luiz Aparecido de Oliveira, Valdomiro Araújo de Souza, Gilberto Álvaro Pimpinatti, Sílvio Antonio Fernandes e Natalício Serpa.

Em 1997 teve início a construção do Grupo Escolar Marechal Rondon, com oito salas de aula. A partir disso, fez-se necessário, então, criar a primeira Delegacia de Ensino de Naviraí, visando normatizar o ensino. A escola Municipal de Ensino Fundamental Marechal Rondon iniciou suas atividades com o nome de Escola Rural Mista de Finoto e situava-se aproximadamente a dez quilômetros de Naviraí, quando ainda era distrito de Caarapó. Entretanto, dado o grande número de crianças em idade escolar, foram elevadas à categoria de Grupo Escolar as Escolas Reunidas que funcionavam com salas de aulas isoladas. Mais tarde, esse veio a ser alterado para Grupo Escolar Marechal Rondon, construído na zona urbana de Naviraí; na década de 1970, foi denominado de Escola Estadual de 1음 Grau Marechal Rondon.

A partir das nossas investigações, constatamos que, somente em setembro de 1992, foi inaugurado o Centro Integrado de Educação - Escola Municipal de Pré-Escola e 10 Grau, primeira instituição de atendimento às crianças de pré-escolar na rede municipal de Naviraí, MS, que posteriormente ficou conhecida como

8 Fonte: http://naviraidiario.com.br 
Creche Mamãe Zezé. Em 25 de janeiro de 1993, a escola passou a denominar-se Centro Integrado de Educação de Naviraí Maria José da Silva Cançado - Ensino de Pré-Escolar e 10 Grau. As monitoras de creche trabalharam até a mudança da legislação e a consequente exigência de formação, em nível normal, para atuarem na educação das crianças naquele espaço.

Com nossas entrevistas, foi possível saber que as monitoras tinham desconhecimento em relação à atividade de monitoria de creche, conforme mencionado por Sônia. A monitora de creche relata: "[Eu] não tinha noção nenhuma! Não tinha ideia de como seria o trabalho, mas depois a gente foi lá conhecer e foi se adaptando" (Sônia).

Sobre a mesma temática, obtivemos o relato de Vera, o qual nós expomos a seguir:

Quando eu iniciei, todas nós, ninguém sabia! Quando a gente vê um regulamento, um edital de concurso a gente fazia! Porque estava desempregada, precisava trabalhar! E aquele concurso a gente não sabia, ninguém sabia naquele tempo o que era monitor de creche. Todas nós fizemos o concurso para começar a trabalhar e nossa! [risos] [pausa]. Nossa que surpresa, porque era coisa de louco a Educação Infantil naquele tempo!

Ciente de que o trabalho seria direcionado ao atendimento de crianças, Vera ainda relata: "[...] naquele tempo a gente era babá mesmo! As creches eram depósitos de crianças, as crianças saíam de lá adolescentes. Eles entravam bebês e os pais largavam lá. Deixavam lá e saíam de lá adultos, com quase 10 anos de idade". Podemos considerar na sua fala que ela percebia a creche como um lugar de ação assistencial, que atendia à demanda das crianças sem muita preocupação com a qualidade e a formação da criança, enfatizando os cuidados e a guarda delas. Tais concepções nos informam sobre as prioridades naquele momento histórico do atendimento à educação da criança pequena no país.

A aprovação da LDBEN (BRASIL, 1996), como nós apontamos na seção anterior, começou imprimir algumas mudanças, dando destaque especial à educação de crianças de 0 a 6 anos, situando o atendimento às crianças como a primeira etapa da Educação Básica e denominando este segmento por Educação Infantil. Dessa forma, os municípios ficam responsáveis por ofertar essa etapa de educação, mas na ordem de prioridades teremos, primeiramente, o Ensino Fundamental (Art. 8o e Art. 11 da LDBEN) e, depois, a Educação Infantil. 
A partir deste movimento da legislação, passa a ser discutida uma nova identidade do educador que atua nas instituições de Educação Infantil, identidade exigida pelas novas leis. Tais critérios vinham sendo incorporados aos documentos do Ministério da Educação desde 1994 e culminaram no texto da LDBEN n. 9.394 (BRASIL, 1996), que passa a compreender como docente o profissional com formação em Nível Superior, mas, por ora, admite-se uma formação mínima em nível médio na modalidade normal (Art. 62 da referida LDB). Andréa aponta: "[...] eu fiquei como monitora dez anos trabalhando na creche. Depois de dez anos, fui para a biblioteca e depois prestei o concurso para professora".

Pelas entrevistas, foi possível entendermos que os encaminhamentos acerca da formação docente, para as monitoras de creche no município de Naviraí, MS, não aconteceram conforme o previsto na política de formação. A prefeitura da cidade optou por fazer um novo concurso para efetivar as pessoas que trabalhavam nas creches, e a legislação mudou sua atuação profissional via o referido concurso. Assim, no dia 31 de março de 2000, as monitoras da Creche Mamãe Zezé foram enquadradas em uma nova categoria de trabalho, exercendo outro tipo de cargo e função, com horários e salários distintos, como assistentes administrativas de escola, exercendo tarefas na biblioteca ou secretaria.

Sônia se pronunciou acerca da questão no relato a seguir: "[...] quando saí da Creche eu assumi a biblioteca aqui, fiz cursos de bibliotecária. Trabalhei um tempo na biblioteca, que foi desativada por falta de sala de aula [...]". Compreendemos que, aos poucos, a biblioteca da escola foi sendo desativada para ceder espaço para mais salas de aula, e Sônia foi se deslocando da função para a secretaria da escola.

A existência da figura de um profissional com a nova formação exigida substituiu as antigas monitoras, e a sua condição profissional foi alterada, a partir da formação e em decorrência da organização da unidade municipal de Educação Infantil, que, no caso específico do município de Naviraí, MS, priorizava uma política de concurso para os cargos a serem ocupados nas suas unidades educativas. Essa nova realidade pode ser encontrada no seguinte excerto da entrevista de Sandra:

As meninas da primeira turma de Normal Superior, algumas fizeram concurso, passaram e foram se encaixando nas escolas. Eu, que fiquei no administrativo, fui ficando! Quando teve o concurso de 2008, eu ainda estava estudando e não tinha como eu fazer o concurso. Eles vão querer o diploma. Então eu não fiz, e fui ficando! Na época eu gostava muito, mas 
me arrancaram isso! Decidi não fazer esse último concurso agora em 2016 $e$, assim, alguns de nós ficamos!

Sobre as relações de interdependência que passam a ser constituídas e exercidas a partir da nova legislação, refletimos com Elias (2006, p. 90) que "[...] o ajustamento entre instituições e necessidades em sociedade em constante mudança nunca é completo. [...] e os problemas são apresentados ao indivíduo pela rede de funções sociais na qual ele ingressa, com suas disparidades inerentes entre meios e fins". Sob esse ângulo, ao ouvirmos os relatos das mulheres monitoras, percebemos os entrelaçamentos entre a objetividade de implantação da norma e a subjetividade expressa na fala das entrevistadas, especialmente, ao descreverem os sentimentos e ressentimentos vividos em função da transição no período, o qual alterou suas trajetórias e condições profissionais.

O conhecimento apreendido nos anos de trabalho com as crianças garantiu às monitoras uma margem de poder sobre as profissionais que assumiram a função que elas realizavam. Segundo as antigas monitoras de creche, as educadoras agora denominadas professoras - que as substituíram não tinham nenhuma experiência com as crianças. Tal fato foi apontado pelas monitoras de creche, quando disseram que a maioria das educadoras eram meninas e que ainda não tinham filhos, sendo esse, então, um problema visto como falta de experiência docente, o que nos leva a refletir acerca da naturalização da profissão, ou seja, o gênero feminino seria garantia para o exercício profissional com a infância (LOURO, 2011).

As monitoras, ao lançarem luz sobre o perfil das novas profissionais, demonstram acreditar que a condição de mães poderia Ihes assegurar uma qualificação melhor para o trabalho em creche e, em contrapartida, a característica de mulher sem filhos seria uma condição ligada à inexperiência ou incapacidade para a docência. Nesse sentido, Louro (2011) elucida acerca de todo este processo, apontando que se a maternidade é, de fato, o destino primordial das mulheres, o magistério passa a ser representado, também, como uma forma extensiva da maternidade. Em outras palavras "[...] cada aluno ou aluna vistos como um filho ou uma filha 'espiritual'" (LOURO, 2011, p. 450).

Ainda de acordo com Louro (2011), a história das mulheres em sala de aula é constituída e constituinte de relações sociais de poder. É mais adequado compreender as relações de poder envolvidas nessa e em outras histórias como 
imbricadas em um tecido social, de tal forma que os diversos sujeitos sociais exercitam e sofrem efeitos de poder. Todos são, ainda que de modos diversos e desiguais, controlados e controladores, capazes de resistir e de se submeterem. Assim, não é possível identificar essas mulheres - monitoras de creche - como apenas subjugadas ou frágeis, o perfil de mãe/professora que lhe foi desejado foi, muitas vezes, subvertido e rejeitado por elas. E essas relações de poder, em constante alteração, possibilitaram constituir a monitora/professora de crianças.

Dessa forma, entendemos que ser professor/a da Educação Infantil sempre foi considerado como uma profissão menos valorizada diante das habilitações para professor/a de Ensino Fundamental, Ensino Médio e Ensino Superior, situação perceptível até mesmo dentro das instituições de Educação Infantil pelas profissionais que atuavam/atuam na área.

Quando aceitamos ser chamadas de tias, monitoras, recreadoras, berçaristas e não de professoras, quando não questionamos as relações dicotômicas entre cuidado e educação, quando aceitamos que a remuneração salarial seja inferior à de outro profissional da educação, quando não lutamos pelos mesmos direitos que qualquer outro profissional, estamos sendo coniventes com o que foi construído e perpetuado ao longo da história do atendimento da criança pequena no Brasil. Estas são algumas das inúmeras situações vivenciadas pelos profissionais da Educação Infantil, que causam um contraste entre o que foi tradicionalmente reconhecido como o ser professor/a e a técnica apreendida e aprimorada para a educação da criança na pequena infância.

Cada uma das monitoras de creche, participantes da nossa pesquisa, exerceu individualmente uma função, mas também compôs um grupo com muitas relações interdependentes que possibilitavam aproximações e distanciamentos, de acordo com os interesses tanto individuais como coletivos em cada figuração (ELIAS, 2006). Nesse sentido, foi possível percebermos em seus relatos o estereótipo da tia, aquela que tira a chupeta, ou seja, não era a professora, mas alguém que substituía a tarefa da família, apontando que "[...] a função de educador de crianças pequenas foi exercida por muito tempo por profissionais que não obtinham valorização de sua função pela sociedade" (PINTO; FLORES, 2017, p. 246).

A figura das educadoras infantis que atuavam com as crianças menores prevaleceu na tradição do mito da mulher como educadora por ser mãe "[...] 'naturalmente' educadora nata, passiva, paciente, amorosa, que sabe agir com 
bom senso, é guiada pelo coração, em detrimento da formação profissional" (ARCE, 2001, p. 182). Tal perfil, construído historicamente, requereu de nossas entrevistadas que buscassem uma formação profissional específica, pois seus relados demonstraram que, por muitos momentos, sentiam-se reconhecidas apenas como babás.

Ainda acerca das expressões dos relatos, vale trazermos aqueles que reforçam a imagem do mito da professora de criança pequena pautada no sentimento, ou seja, aquela mulher que gosta de crianças exerceria a atividade profissional com mais competência (ARCE, 2001). Tal percepção está atrelada ao trabalho da mãe, da mulher que cuida de forma abnegada, não se importando com as condições de salário ou da carreira, concepções fundadas no chamado mito do amor materno, pesquisado por Badinter (1985). Para a autora, esse sentimento maternal foi sendo construído historicamente, colocando as mulheres em uma posição alinhada e submissa com o envolvimento e o trabalho com crianças.

A maternidade está atrelada ao ofício de ser professora, também, por lembrar a responsabilidade biológica das mulheres em termos da reprodução, cuidado e continuidade da espécie. Nesse viés, Sarat (2015, p. 28) aponta, em sua análise da atuação do trabalho docente com crianças em outros países na América Latina, que "[...] o trabalho de atendimento às crianças pequenas era feito em geral por mulheres, a grande maioria sem formação e firmada nos conceitos maternal e biológico, ou seja, bastava ser mulher e mãe para estar habilitada a trabalhar com criança". Diante disso, podemos afirmar que a inserção das muIheres como professoras no mercado de trabalho passou a ser vista como uma extensão da maternidade, reforçando as caraterísticas consideradas femininas, como vocação, paciência e habilidade, essenciais para lidar com as crianças, bem como foram enaltecidas características como docilidade, meiguice e recato como fundamentais para tratarem com as pequenas e os pequenos (CAMPOS, 2018).

O profissional da Educação Infantil foi, e muitas vezes ainda é até hoje, um outsider da profissionalização docente. Na constituição dessa profissão, ficou implícita ao fato de ser professor de crianças pequenas uma ideia de profissional menor, que não precisa de uma boa formação, mas uma instrução mínima que o habilitaria ao trabalho com os pequenos. Ou seja, esta ocupação, por muito tempo, esteve vinculada ao perfil da maternidade e do cuidado com a criança. Mesmo a formação em serviço, disponibilizada nas instituições de Educação Infantil, enfocou 
historicamente mais conteúdos e procedimentos esperados para as crianças no Ensino Fundamental, tais como a Alfabetização, do que as habilidades e competências voltadas para as necessidades das crianças pequenas.

Retomando as monitoras de Naviraí, MS, elas assumiram o concurso em 1996 e atuaram sozinhas com as crianças até o ano de 2005, quando foi realizado o concurso para as educadoras. Nesse tempo, a maioria das monitoras já estava cursando o Normal Superior, mas não conseguiram terminar o curso em tempo para concorrer com as profissionais que já tinham o Magistério. Sendo assim, a oportunidade para que as monitoras de creche retornassem à Educação Infantil surgiu somente no referido concurso para professor da Educação Infantil, mas nesse ínterim algumas desistiram pelo caminho ou preferiram ficar com o cargo de administrativo escolar.

As monitoras relataram que lhes faltou resistir, faltou bater o pé, faltou lutar mais pelos seus direitos e, quem sabe, acreditar que eram capazes de buscar novos conhecimentos. Não tiveram informações sobre o que estava sendo proposto pelo Ministério da Educação, e quais eram as propostas para uma formação profissional em serviço. E faltou, principalmente, acreditarem que já eram professoras e precisavam somente de uma formação que Ihes possibilitaria assumirem o que de fato já tinham por direito.

\section{CONSIDERAÇÕES FINAIS}

Segundo Elias (2008), os indivíduos estão imbricados em uma "teia" de acontecimentos individuais e sociais. Nesse sentido, não procuramos na sociedade os fenômenos como "coisas" estáticas e não mutáveis, mas sim percebemos a sociedade sendo constituída e se constituindo a partir das relações entre indivíduos. Percebemo-nos como indivíduos que se aproximam e se distanciam, conforme o jogo de interesses e necessidades, "somos nós próprios um ser entre os outros" (ELIAS, 2008, p. 13).

Assim, depreendemos que as políticas educacionais pensadas para o atendimento à criança pequena geraram uma alteração na carreira das profissionais, as monitoras de creche de Naviraí, MS, e que tal fato se refletiu em suas trajetórias de formação docente. Ressaltamos que as monitoras de creche poderiam ter ficado no esquecimento da história da Educação Infantil do referido município, não fossem os relatos de suas vivências do cotidiano escolar e suas contribuições 
recolhidas e veiculadas por meio da pesquisa científica. Nesse sentido, precisamos enaltecer nosso compromisso em dar visibilidade às trajetórias de profissionalização docente de mulheres educadoras de Naviraí, MS, ampliando e aprofundando nossos estudos, garantindo que suas histórias venham à tona, contribuindo para a escrita da escrita da História da Educação, bem como da História das Mulheres e as discussões de gênero que permeiam a profissão de professoras/es.

Com isso, compreendemos que rememorar os aspectos envolvidos no percurso de suas vidas e trajetórias profissionais possibilitou o entendimento de como as figurações, quer sejam, as redes de interdependência, foram constituídas pelas muIheres educadoras e ao mesmo tempo as constituíram, trazendo à tona questões de gênero e poder inerentes aos diferentes tempos e espaços de trabalho e formação.

\section{REFERÊNCIAS}

ALBERTI, Verena. História dentro da História. In: PINSKY, Carla B. Fontes históricas. 2. ed. São Paulo: Contexto, 2006.

ARCE, Alessandra. Documentação oficial e o mito da educadora nata na Educação Infantil. Cadernos de Pesquisa, São Paulo, n. 113, p. 167-84, 2001. Disponível em: http://www. scielo.br/pdf/cp/n113/a09n113.pdf. Acesso em: 2 fev. 2019.

BADINTER, Elisabeth. Um amor conquistado: o mito do amor materno. Rio de Janeiro: Nova Fronteira, 1985.

BONI, Valdete; QUARESMA, Silvia Jurema. Aprendendo a entrevistar: como fazer entrevistas em ciências sociais. Em Tese, Florianópolis, v. 2, n. 1, p. 68-80, jan. 2005. ISSN 1806-5023. Disponível em: https://periodicos.ufsc.br/index.php/emtese/article/ view/18027/16976. Acesso em: 23 jan. 2019.

BRASIL. Lei n. 12.796, de 4 de abril de 2013. Altera a Lei n. 9.394, de 20 de dezembro de 1996, que estabelece as diretrizes e bases da educação nacional, para dispor sobre a formação dos profissionais da educação e dá outras providências. Brasília-DF, 1996. Disponível em: http://www.planalto.gov.br/ccivil_03/_Ato2011-2014/2013/Lei/L12796. htm. Acesso em: 3 mar. 2019.

BRASIL. Lei n. 9.394, de 20 de dezembro de 1996. Estabelece as diretrizes e bases da educação nacional. Brasília-DF, 1996. Disponível em: http://www.planalto.gov.br/ccivil_03/ leis/I9394.htm. Acesso em: 3 mar. 2019. 
BRASIL. Ministério da Educação e do Desporto. Por uma política de formação do profissional de Educação Infantil. Brasília-DF: MEC/SEF/DPE/COEDI, 1994a.

BRASIL. Ministério da Educação e do Desporto. Política de Educação Infantil. Brasília: MEC/SEF/DPE/COEDI, 1994b.

BRASIL. Ministério do Desenvolvimento Social e Combate à Fome. Lei Orgânica de Assistência Social. Brasília-DF: MPAS, 1993.

BRASIL. Constituição da República Federativa do Brasil de 1988. Brasília-DF, 1988. Disponível em: http://www.planalto.gov.br/ccivil_03/constituicao/constituicao.htm. Acesso em: 3 mar. 2019.

CAMPOS, Míria Izabel. Tempos de escritas: memoriais de infância, docência e gênero. 188 f. 2018. Tese (Doutorado em Educação) - Universidade Federal da Grande Dourados, Dourados, MS, 2018.

CUNHA, Charles M. Memórias docentes: convocações do presente. Jundiaí: São Paulo: Paco, 2017.

CUNHA, Maria Isabel. Conta-me agora! As narrativas como alternativas pedagógicas na pesquisa e no ensino. Revista Faculdade de Educação, São Paulo, v. 23, n. 1/2, p. 185-95, jan./dez. 1997. Disponível em: http://www.scielo.br/scielo.php?script=sci_arttext\&pid =S0102-25551997000100010. Acesso em: 9 fev. 2019.

ELIAS, Norbert. Introdução à sociologia. Lisboa: Edições 70, 2008.

ELIAS, Norbert. Escritos e ensaios. Rio de Janeiro: Jorge Zahar, 2006. (Estado, processo, opinião pública, v. 1).

ELIAS, Norbert. O processo civilizador. Rio de Janeiro: Zahar, 1993. (Formação do Estado e civilização, v. 2).

ENGUITA, Mariano F. A ambiguidade da docência: entre o profissionalismo e a proletarização. Teoria \& Educação, Porto Alegre, n. 4, p. 41-61, 1991.

FREITAS, Sônia M. História oral: possibilidades e procedimentos. 2. ed. São Paulo: Associação Editorial Humanitas, 2006.

GONÇALVES, Albertino. Métodos e técnicas de investigação social I: programa, conteúdo e métodos de ensino teórico e prático. Cidade: UMinho, 2004. 
LANG, Alice B. Silva Gordo. História oral: muitas dúvidas, poucas certezas e uma proposta. In: MEIHY, José Cícero Sebe Bom (Org.). (Re)introduzindo a história oral no Brasil. São Paulo: Xamã, 1996. p. 33-47.

LOURO, Guacira. L. Mulheres na sala de aula. In: PRIORE, Mary Del (Org.). História das mulheres no Brasil. 10. ed. São Paulo: Contexto, 2011. p. 443-81.

MONTIEL, Larissa Wayhs Trein. Da Assistência à Educação Infantil: a transição do atendimento à infância no município de Naviraí - MS (1995-2005). 2019. 233 f. Tese (Doutorado em Educação) - Universidade Federal da Grande Dourados, Dourados, MS, 2019.

NAVIRAÍ (Cidade). Centro Integrado de Educação Infantil [CIEI] Maria José Da Silva Cançado. Projeto Político Pedagógico. Naviraí, 2015.

NÓVOA, Antonio. Para um estudo sócio histórico da gênese e desenvolvimento da profissão docente. Teoria \& Educação, Porto Alegre, n. 4, p. 109-39, 1991.

OZELLA, Sérgio. Pesquisar ou construir conhecimento. O ensino da pesquisa na abordagem sócio histórica. In: BOCK, Ana Mercês (Org.). A perspectiva sócio-histórica na formação em psicologia. Petrópolis: Vozes, 2003. p. 113-31.

PAVAN, Ruth. Currículo e exclusão social: a perspectiva das alunas/professoras do PIBID de Pedagogia. Série-Estudos, Campo Grande, v. 23, n. 49, p. 193-206, set./dez. 2018.

PINTO, Adriana F. E.; FLORES, Maria L. R. Formação inicial e valorização das professoras na Educação Infantil. In: ALBUQUERQUE, Simone S.; FELIPE, Jane.; CORSO, Luciana V. (Org.). Para pensar a educação infantil em tempos de retrocessos: lutamos pela educação infantil. Porto Alegre: Evangraf, 2017.

SARAT, Magda. História da formação de professoras para a infância: experiências no Brasil e na Argentina. Revista Teoria e Prática da Educação, Maringá, v. 18, n. 1, p. 23-36, jan./ abr. 2015.

SARAT, Magda; SANTOS, Reinaldo. História Oral como fonte: apontamentos metodológicos e técnicos da pesquisa. In: COSTA, Célio J.; MELO, José J. P.; FABIANO, Luiz H. Fontes e métodos em história da educação. Dourados: UFGD, 2010. p. 49-78.

SOUZA, José Edimar. Memórias de uma trajetória formativa na Escola Normal de Sapiranga/RS - Brasil (1963- 1975). In: ENCONTRO NACIONAL DE HISTÓRIA ORAL, 13., 1-4 maio 2016, Porto Alegre. Anais [...]. Porto Alegre: UFRGS, 2016. Disponível em: https:// 
www.encontro2016.historiaoral.org.br/resources/anais/13/1461899266_ARQUIVO_ textocompletosubmetido.pdf. Acesso em: 10 fev. 2021.

THOMPSON, Edward P. A miséria da teoria ou o planetário de erros: uma crítica ao pensamento de Althusser. Rio de Janeiro: Zahar editores, 1981.

THOMPSON, Paul. A voz do passado: História Oral. 3. ed. Rio de Janeiro: Paz e Terra, 2002.

\section{Sobre os autores:}

Larissa Wayhs Trein Montiel: Doutorado e mestrado em Educação pela Universidade Federal da Grande Dourados (UFGD). Graduação em Pedagogia pela UFGD. Professora Adjunta da Fundação Universidade Federal de Mato Grosso do Sul (UFMS), campus Naviraí. Pesquisadora do Grupo de Estudos e Pesquisa em Prática Educativa e Tecnologia Educacional (GEPPETE), sendo a líder da linha de pesquisa Práticas Educativas e Formação Docente. Atua principalmente nos seguintes temas: História da Educação, Formação de Professores e Práticas Educativas na Educação Infantil e Ensino Fundamental. E-mail: larissa.montiel@ufms.br, Orcid: https://orcid.org/0000-0001-9437-1440

Míria Izabel Campos: Doutorado e mestrado em Educação pela Universidade Federal da Grande Dourados (UFGD). Especialização em Psicologia Educacional pela Pontifícia Universidade Católica de Minas Gerais (PUC-MINAS). Graduação em Psicologia pela Universidade Federal de Minas Gerais (UFMG). É professora adjunta na UFGD, lotada na Faculdade de Educação (FAED). Atualmente é membro titular da Comissão Permanente de Pesquisa da Faculdade de Educação (FAED) na UFGD e membro titular da Comissão Permanente de Apoio ao Curso de Pedagogia. Participa da Associação Nacional de Pós-Graduação e Pesquisa (ANPEd), atuando como parecerista ad hoc da ANPEd Regional Centro-Oeste, Grupo de Trabalho (GT) 23: Gênero, Sexualidade e Educação; e participa da Associação Brasileira de Pesquisa (Auto)Biográfica (BIOGraph). É Vice-Líder do Grupo de Pesquisa Educação e Processo Civilizador (GPEPC). E-mail: miria.iza.campos@gmail.com, Orcid: https://orcid.org/0000-0002-3259-6182

\section{Recebido em: 03/03/2020 Aprovado em: 28/03/2021}


